\title{
COMPARISON OF TALC PLEURODESIS VERSUS BLEOMYCIN IN MALIGNANT PLEURAL EFFUSION
}

\author{
GONI MO ${ }^{1}$, ISLAM MA ${ }^{2}$, ALAM $^{3}$, HOSSAIN MZ ${ }^{4}$, ISLAM T ${ }^{5}$, ISLAM KS ${ }^{6}$, MAHMUD HA ${ }^{7}$, \\ KABIR MA ${ }^{8}$
}

\begin{abstract}
Back ground: Malignant pleural effusion can cause significant morbidity to terminal patients. Drainage and control pleural effusion can provide great palliation and improve the quality of life of these patients. The purpose of this study was to evaluate which agent, bleomycin or talc pouring for pleurodesis is superior in terms of effectiveness, safety and cost.

Methods: It is a prospective randomized clinical trial from January 2013 to December 2014. A series of 38 patients entered in this trial. Inclusion criteria was diagnosed case of malignant pleural effusion either by fluid cytology or by pleural biopsy. Exclusion criteria was trapped lung, loculated effusions and life expectancy $<1$ month. Five grams of talc in $50 \mathrm{ml}$ of normal saline or 1 unit per $\mathrm{kg}$ body weight of bleomycin mixed in $50 \mathrm{ml}$ of normal saline, was administered via chest tube thoracostomy after minimum drainage $<100 \mathrm{ml}$ daily in each patient. Treatment success was defined as the absence of recurrent pleural effusion on the chest radiography 1 month after pleurodesis.
\end{abstract}

Results: Treatment success was achieved in 16 out of 18 patients (89\%) in talc slurring group versus 14 out of 20 patients (70\%) in the bleomycin group ( $p=0.154)$. Fever, pain and hypersensitivity were the side effects of pleurodesis.

Conclusions: These results reflect that talc use was more effective than bleomycin in preventing early recurrence of malignant pleural effusions. Pleurodesis with talc instate of bleomycin can result in significant cost effective.

J Dhaka Med Coll. 2019; 28(1) : 42-48

\section{Introduction}

More than 25\% of all pleural effusion are secondary to cancer and 35\%of patients with lung cancer, $25 \%$ patient breast cancer, $10 \%$ patients are due to lymphoma and $12 \%$ of patients with adenocarcinoma of unknown primary site $^{1}$. Carcinoma of lung, breast and lymphomas are account for approximately $75 \%$ of malignant pleural effusion ${ }^{2}$. Metastatic overian cancer is fourth leading cause of malignant pleural effusion ${ }^{2}$. The mechanism of malignant pleural effusion is due to obstruction of lymphatic vessels and nodes, direct malignant infiltration of the pleura and biochemical mechanisms associated with increased vascular permeability due to vasoactive factors released by tumors cells ${ }^{5}$.

Patients may present with cough, dyspnea, heaviness in the chest and chest pain ${ }^{3}$.

1. Dr. Mohammad Osman Goni, Assistant Professor, Department of Thoracic surgery, Dhaka Medical College and Hospital, Dhaka, Bangladesh.

2. Dr. Mohammad Aminul Islam, Associate Professor, Department of Respiratory Medicine, Dhaka Medical College and Hospital, Dhaka

3. Dr. Kamrul Alam, Professor \& Head, Department of Thoracic surgery, Dhaka Medical College and Hospital, Dhaka

4. Dr. Mohammad Zaid Hossain, Associate Professor, Department of Medicine, Dhaka Medical College and Hospital, Dhaka

5. Dr. Tazul Islam, Resident (MS Course), Department of Thoracic surgery, Dhaka Medical College and Hospital, Dhaka

6. Dr. Kazi Saiful Islam, Associate Professor, Department of Thoracic surgery, Dhaka Medical College and Hospital, Dhaka

7. Dr. Hossain Al Mahmud, Indoor Medical Officer, Department of Thoracic Surgery, Dhaka Medical College and Hospital, Dhaka

8. Dr. Md. Alamgir Kabir, Junior Consultant, Upazila Health Complex, Tongi

Correspondence: Dr. Mohammad Osman Goni, Assistant Professor, Department of Thoracic Surgery, Dhaka Medical College \& Hospital, Dhaka, Mobile no.01720106576, Email: og96643@gmail.com

Received: 10 February $2019 \quad$ Revision: 02 March 2019

Accepted: 30 Mach 2019

DOI: https://doi.org/10.3329/jdmc.v28i1.45755 
Malignant pleural effusion can be serous or hemorrhagic, exudative and diagnosed primarily by demonstrating malignant cells in the pleural fluid or pleural biopsy ${ }^{1}$. Treatment of malignant pleural effusion is strictly palliative. Prompt diagnosis and therapy are essential $^{1}$. Tube thoracostomy with pleurodesis has become the most therapeutic approach ${ }^{3}$. When pleurodesis is performed, as a procedure a chest tube is generally inserted ${ }^{4}$. A large bore tube should be considered especially when used talc ${ }^{5}$. Chest tube size is $28 \mathrm{Fr}$. Tetracycline, doxycycline, talc and bleomycin are the agents used most commonly for pleurodesis ${ }^{3}$. However, parenteral tetracycline is no longer commercially available for pleurodesis, oxytetracline is available but needs repeated administration $^{3}$. Bleomycin and talc remain therapeutic options ${ }^{3}$.

Talc is Inexpensive, highly effective and easily administered as a slurry instilled through a chest tube. Bleomycin can also use in pleurodesis as a slurry ${ }^{1}$. A prospective randomized trial was designed to compare the efficacy, safety and cost effectiveness of bleomycin VS talc slurry, given via bed side thoracostomy tube, in the treatment of symptomatic malignant pleural effusion ${ }^{3}$.

\section{Patients and Methods}

A prospective, randomized study was conducted comparing talc pleurodesis and bleomycin in treatment of symptomatic malignant pleural effusions. Thirty-eight patients with malignant pleural effusions were enrolled after informed written consent from January 2013 to December 2014 in Thoracic surgery department of Dhaka Medical College and Hospital. Patients with confirmed diagnosis of malignant pleural effusions by fluid cytology or pleural biopsy were included. Patients with trapped lung, recurrent effusions, loculated effusions and patient's life expectancy $<1$ month were excluded.

Among 38 patients, 3 patients' tube thoracostomy was done outside hospitals but with diagnosis of malignant pleural effusions. In the other 35 patients, tube thoracostomy was done at the mini operation theatre which is situated close to the patients ward with local anesthesia. The thoracostomy tube remained on $-20 \mathrm{~cm}$ under water sealed drainage bag. Drainage and lung expansion were assessed by chest radiograph over next 24 hours. All patients are encouraged for breathing exercise by using incentive spirometer. Patients eligible were then randomized, one patient with talc, next patients with bleomycin pleurodesis. The preparations consist of $20 \mathrm{ml} 1 \%$ lidocaine and either $45 \mathrm{U}$ of bleomycin or $5 \mathrm{gm}$ of talc diluted to $50 \mathrm{ml}$ normal saline solution. The talc containing bottle is heated in the stream sterilization and verified sterility by using the biological indicator Bacillus subtilis.

For pleurodesis, the sclerosing agent was injected into the thoracostomy tube and tube was then flushed with $30 \mathrm{ml}$ normal saline solution. Next the tube was then clamped for 6 hours. In the meantime, the patient was asked to change posture, like Trendelenburg, reverse Trendelenburg, supine, prone, right and left lateral position for every 10-15-minute interval. After 6 hour the tube was then unclamped and keep the tube under water sealed drainage bag and advised the patient for vigorous breathing exercise.

Serial radiographs were used to ensure appropriate lung re-expansion. The thoracostomy tube was generally removed 24 hour following treatment. The patients received chest radiographs immediately following tube removal and again follow up. Patients were assessed before and after treatment regarding dyspnea and pain. Pain, dyspnea and chest radiographs were all assessed and evaluated before and after treatment.

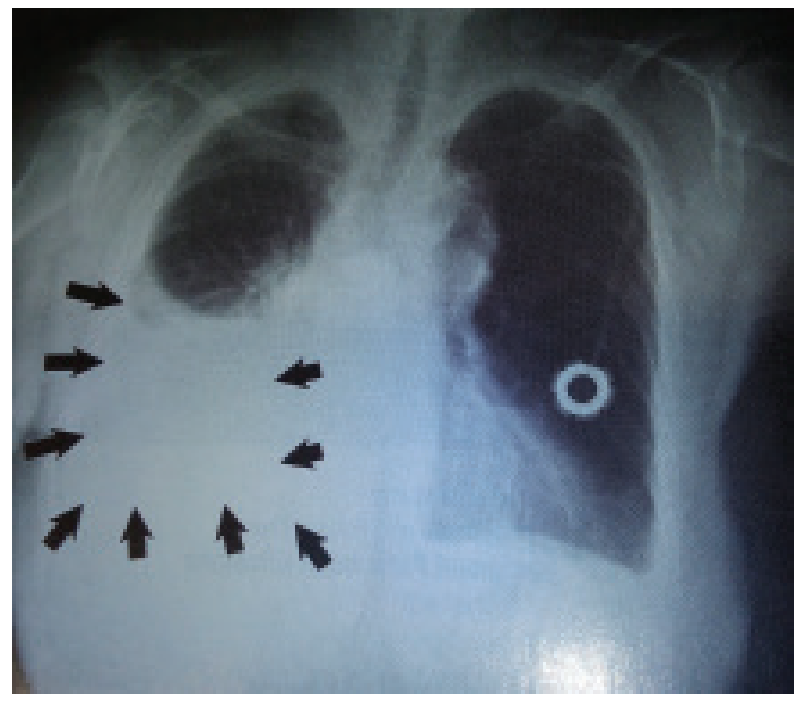

Fig.-1: $X$-ray chest posterior anterior view showing right sided pleural effusion. 


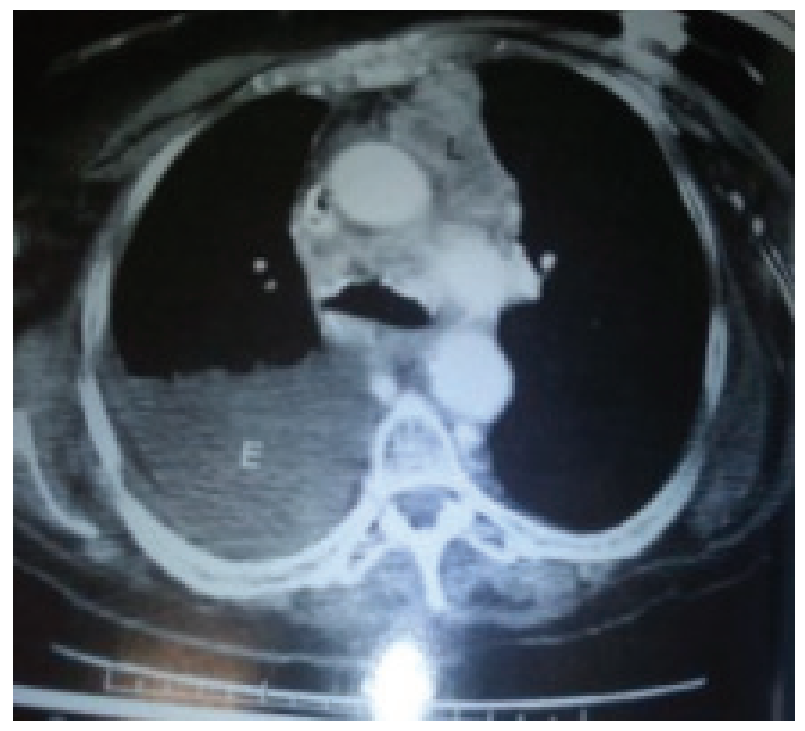

Fig.-2: $C T$ scan of the chest showing RT sided pleural effusion.

Follow up is traditionally difficult in these patients given their underlying diseases and life expectancy. Follow up OPD visits were scheduled at 4 weeks, 8 weeks and 12 weeks. For the first 12 weeks, patients were called on a weekly interval. After initial 12 weeks, patients were called on every other week. Chest radiographs, interval history and physical examination were obtained at each visit.
Statistical analysis was as follows, age, hospital stays, pain score, dyspnea score were compare between groups using unpaired students t-test, and sex, side, complications and Radiographs scores were compared by using Chi-square test.

\section{Results}

Thirty-eight patients under went pleurodesis, 14 out of 20 patients $(70 \%)$, in the bleomycin group, whereas 16 out 18 patients (89\%) in the talc slurry group. Fever, pleural infection, pain, hypersensitivity reaction and wound infection were the only side effects of pleurodesis in both groups. Among fifty-two patients, thirty-eight patients who, under went procedures were available for follow up after hospital discharge. Six patients who, under went eight procedures were not available for post treatment assessment. Two patients who, under went, bilateral pleurodesis died prior to hospital discharge. The additional six patients were unavailable for follow up. From the results of Table 1 study, bleomycin group had more lung primary $(60.0 \%)$, otherwise the groups were similar with respect to age $(p=0.071)$, sex $(p=0.203)$, side of pleurodesis $(p=0.111)$, and number of hospitals stay $(\mathrm{p}=0.105)$. Side effects between the two groups, (Table-2) was not statistically significant.

Table-I

Description of variables of the study subjects ( $n=38)$

\begin{tabular}{llccc}
\hline Variable & & $\begin{array}{c}\text { Bleomycin } \\
(\mathrm{n}=20)\end{array}$ & $\begin{array}{c}\text { Talc } \\
(\mathrm{n}=18)\end{array}$ & p-value \\
\hline Age, yr, mean & $53.5 \pm 11.45$ & $46.9 \pm 10.15$ & 0.071 & \\
Sex & Male & $13(65.0 \%)$ & $8(44.4 \%)$ & \\
& Female & $7(35.0 \%)$ & $10(55.6 \%)$ & 0.203 \\
Side & Left & $6(30.0 \%)$ & $10(55.6 \%)$ & \\
& Right & $14(70.0 \%)$ & $8(44.4 \%)$ & 0.111 \\
Pathology & Lung & $12(60.0 \%)$ & $6(33.3 \%)$ & \\
& Breast & $2(10.0 \%)$ & $6(33.3 \%)$ & 0.233 \\
& Ovarian & $2(10.0 \%)$ & $2(11.1 \%)$ & \\
Hospital stays & Other & $4(20.0 \%)$ & $4(22.2 \%)$ & \\
& Mean \pm SD & $12.4 \pm 1.36$ & $13.5 \pm 2.31$ & 0.105 \\
& Median & 11 & 12 & \\
\hline
\end{tabular}


Table-II

Description of complications between two groups

\begin{tabular}{lccc}
\hline Variable & $\begin{array}{c}\text { Bleomycin } \\
(\mathrm{n}=20)\end{array}$ & $\begin{array}{c}\text { Talc } \\
(\mathrm{n}=18)\end{array}$ & p-value \\
& No. $(\%)$ & No. $(\%)$ & \\
\hline Recurrence of effusion post discharge & $6(30.0 \%)$ & $4(22.2 \%)$ & 0.586 \\
Pleural infection & $1(5.0 \%)$ & $2(11.1 \%)$ & 0.485 \\
Wound infection & $0(0.0 \%)$ & $3(16.7 \%)$ & 0.050 \\
Hypersensitivity reaction & $1(5.0 \%)$ & $0(0.0 \%)$ & 0.363 \\
Fever & $0(0.0 \%)$ & $1(5.6 \%)$ & 0.285 \\
\hline
\end{tabular}

Table-III

Chest Radiographs*

\begin{tabular}{lccc}
\hline Variable & $\begin{array}{c}\text { Bleomycin } \\
(\mathrm{n}=20)\end{array}$ & $\begin{array}{c}\text { Talc } \\
(\mathrm{n}=18)\end{array}$ & p-value \\
& No. $(\%)$ & No. $(\%)$ & \\
\hline Post treatment score 1 or 2 & $14(70.0 \%)$ & $16(89.0 \%)$ & \\
Post treatment score 3 or 4 & $6(30.0 \%)$ & $2(11.0 \%)$ & 0.154 \\
\hline
\end{tabular}

*Scored at follow-up with the following scale: (1) no effusion; (2) minimal effusion (<10\% compared to before intervention); (3) moderate effusion (10 to 49\% compared to before intervention); and (4) large effusion (50 99\% compared to before intervention).

Table -IV

Results: pain and Dyspnea Scores before and after treatment

\begin{tabular}{|c|c|c|c|c|c|}
\hline Variable & & $\begin{array}{c}\text { Before } \\
(\mathrm{n}=20) \\
\text { Mean } \pm \text { SD }\end{array}$ & & $\begin{array}{c}\text { After } \\
(\mathrm{n}=18) \\
\text { Mean } \pm \text { SD }\end{array}$ & p-value \\
\hline \multirow[t]{2}{*}{ *Pain } & Bleomycin & $5.5 \pm 1.2$ & & $2.3 \pm 0.57$ & $<0.001$ \\
\hline & Talc & $6.21 \pm 1.4$ & & $3.5 \pm 0.75$ & $<0.001$ \\
\hline \multirow[t]{4}{*}{ \#Dyspnea } & & & $\mathrm{p}$ value & 0.111 & 1.000 \\
\hline & Bleomycin & $3.4 \pm 0.38$ & & $2.1 \pm 0.34$ & $<0.001$ \\
\hline & Talc & $4.0 \pm 0.41$ & & $2.0 \pm 0.21$ & $<0.001$ \\
\hline & & & $p$ value & 0.061 & 0.289 \\
\hline
\end{tabular}

${ }^{*} 0$ is equal to none; and 10 is equal to maximum.

\#Functional class: 1 is equal to none; 2 is equal to moderate to heavy activity; 3 is equal to minimal activity; and 4 is at rest.

Follow up were from seven days to 12 weeks. Pain and dyspnea (Table 4) functional class scores were notable improved in both groups following treatment. However, there was no statistically significant difference between the two groups with respect to degree of improvement. Effusions control was defined objectively as a follow up chest radiographs score 1 or 2 (Table 3 ). There was recurrence of pleural effusion in six patients in bleomycin group and four patients in talc group (Table 2). There was no statistically significant difference between two groups $(p=0.233)$. Three patients in each group had a moderate effusion on follow 
up, but their symptoms were clearly improved and did not require additional intervention. There were three significant recurrence in bleomycin group and one was in talc group. Recurrence in bleomycin group was successfully treated with talc slurry and recurrence in talc group was discharge with indwelling pleural catheter and advised to come after three weeks. The patients discharged with indwelling catheter when came after three weeks was improved and his catheter was removed.

The only significant complications observed (Table 2) were limited wound infections, three in talc slurry groups and none in bleomycin groups $(p=0.050)$, pleural infection one in bleomycin group and two in talc slurry groups, one hypersensitivity reaction in bleomycin group and one fever in talc group. Overall, we had very low morbidity associated with these procedures. We had no cases of respiratory failure, and no deaths directly attributable to pleurodesis.

We also under took a cost analysis of the agents used in our study. The medication cost to our medical centre for talc slurry is 84 taka or US\$1 only whereas for bleomycin 2520 taka or US\$30 per $15 \mathrm{U}$.

\section{Discussion}

The use of various chemical agents including talc and bleomycin for malignant pleural effusions has been reviewed previously. In this randomized study, we showed that both talc slurry and bleomycin are effective in controlling the malignant pleural effusions. These two agents are most commonly used sclerosants and appear to be the most cost effective ${ }^{6}$. Tetracycline, the agent used most commonly previously, is no longer commercially available. Doxycycline has been used as a replacement for tetracycline but two thirds of patient require multiple treatment so its use is not popular ${ }^{3}$.

Recently, two relatively new sclerosing agents, OK 432 and Mitomycin-C have been reported to be effective for pleurodesis ${ }^{8}$. OK 432 is a penicillin treated lyophilized preparation streptococcus pyogenes, type A3, which was developed as an immunotherapeutic agent (Picibanil) for cancer ${ }^{8}$. Mitomycin $\mathrm{C}$ is a chemotherapeutic agent ${ }^{7}$. However, both can be used as effective pleurodesis.

In our study, the talc (Mg3Si4] O10 [OH] 2) we used is a tri layered magnesium sheet silicate. Sterile USP asbestos free talc is currently appropriate for intra pleural use ${ }^{3}$.

F. Muta, et al. in his study was found, talc particles were focally seen in the alveoli, which indicated that the talc particle was absorbed through the visceral pleura. This could lead to development of lung injury or ARDS 7 . However, a recent report by Janssen JP, et al. indicated that the use of large particles talc for pleurodesis in malignant pleural effusions is safe and is not associated with the development of ARDS ${ }^{12}$. Kennedy et al. studied the histological changes following talc slurry pleurodesis ${ }^{13}$. They described that talc administration of the talc slurry caused mesothelial denudation, which followed by a low grade mononuclear cell inflammatory process. Pleural adhesions formed shortly after talc administration and did not increase over time. Therefore, the predominant cause of pleurodesis with talc slurry instillation was an acute pleural injury ${ }^{7,13}$.

Rinaldo JE, at el. In his study has described three cases (one resulting in death) of ARDS attributed to pleurodesis with $12 \mathrm{gm}$ of talc slurry $^{3}, 15$. Another report of Bouchama A, et al. described acute pneumonitis, possibly secondary to talc emboli, following a pleural biopsy in conjunction with pleurodesis $2 \mathrm{gm}$ of talc slurry ${ }^{16}$. One other series of 40 procedures using talc slurry Kennedy L, at el. noted three cases of respiratory failure attributed to pleurodesis ${ }^{17}$. We have not experienced none these complications in our patients. However, based on the adverse effects noted in these reports we should use talc carefully. Talc should not be administered immediately after lung or pleural biopsy due to risk of talc emboli, bilateral simultaneous pleurodesis should be avoided and no more than $5 \mathrm{gm}$ be administered in a single dose.

Bleomycin is an antineoplastic antibiotic from Streptomyces verticillus that binds DNA producing breakage, thus inhibiting DNA synthesis. It is widely used because of its 
sclerosing properties for pleurodesis. Its success at controlling malignant pleural effusions has been examined ${ }^{3}$. The use of intra-pleural bleomycin has also been associated with respiratory failure. Pain, fever, nausea, hemoptysis, fluid accumulation and septic shock, rash, diarrhea are some of the other adverse effects reported with intra-pleural administration of bleomycin ${ }^{8}$. It has been associated with minimal toxic reaction. However, a case report by Siegel RD et al. does described systemic toxicity manifested by alopecia and significant mucosities following pleurodesis in 32-year-old women with malignant pleural effusions and renal failure ${ }^{3}$, ${ }^{14}$. So caution is needed for its use in patients with poor renal function.

Randomized controlled trials are essential for establishing the effectiveness of one sclerosant over another. Two previous studies directly comparing the use of talc slurry and bleomycin for pleurodesis of malignant pleural effusions ${ }^{3}$, 8. They had shown similar efficacy of both agents in reducing recurrence. In the study by Zimmer et al. Success rates as defined by no recurrence or minimal $(<10 \%)$ recurrence at follow up (mean 1.7 months) were $79 \%$ in the bleomycin group, compared to $90 \%$ to the talc group $^{3}$ and in ONG KC, at el. Success rates defined by the absence of recurrent pleural effusions on the chest radiographs 1 month after pleurodesis was achieved $89 \%$ in the talc slurry group and $70 \%$ in the bleomycin group.

The present study shares many similarities in study design with these previous trials, though it is an unique study in that the success rates are defined as radiological recurrence at 1 month post pleurodesis instead of during the period of follow up, which could range from case to case depending on the prognosis of different malignancies as well as compliance with follow up. Follow up is actually very difficult in patients with malignant pleural effusions as their short life expectancy. Even a short follow up period of 4 weeks, one quarter of the patients were missing in the present study.

It is possible to say that all three comparative studies thus far suggest that pleurodesis with talc slurry is more effective than with bleomycin in preventing recurrence of malignant pleural effusions, albeit with a lack of statistical significance.

We encountered no significant problems with pain control or fever during the procedure. One patient in the talc group develop fever with in the three days after pleurodesis compared to none in the bleomycin group was managed by antipyretic drugs. Pain control during the procedures were managed by NSID and low dose opiods. The pleural infection one in bleomycin group and two in talc group was managed by appropriate antibiotics after culture sensitivity of pleural fluid. Wound infection at the site of tube thoracostomy three in talc group and none in the bleomycin group were managed by oral antibiotics. One patient developed hypersensitivity reaction in bleomycin group and none in talc group was managed by steroids and anti-histamin drugs.

There was recurrence of pleural effusions in six patients in bleomycin groups and four patients in talc groups in the follow up period of one month. Three patients in each group had a moderate pleural effusion on follow up, but their symptoms were clearly improved after thoracentesis. Three large effusions were found in bleomycin group and one in talc group. Recurrence in bleomycin group were successfully with talc slurry and recurrence in group was discharged with indwelling catheter. When come back after three weeks was improved, catheter was removed. So, there was no major complications resulting in major mortality or morbidity.

Talc is much less costly agent then bleomycin. Five grams of sterilized talc costs less than US\$ 1 or 84 taka, whereas bleomycin is available at a cost of US\$ 30 OR 2520 taka per 15 U. For an average man of $70 \mathrm{~kg}$, the difference in cost per treatment amounts US\$ 119 or 10,000 takas. So, talc is much cheaper than bleomycin. In our low socio-economic condition's talc will give more benefits for the patients.

\section{Conclusion}

Malignant pleural effusions can have a significant impact on quality of life in patients. We should relieve the patients from their pain 
and dyspnea and we should use simple, safe and cost-effective therapy in these terminal stage patients. Chemical pleurodesis by both bleomycin and talc slurry is highly effective at controlling malignant pleural effusions and decreases the associated symptoms of dyspnea and pain. There were no significant major complications or side effects during these procedures. As talc slurry is notably more cost effective in place of bleomycin can result significant cost savings in our low socioeconomic conditions.

\section{References}

1. Pierre R. Theodore, MD; David Jablons, MD. Thoracic Wall, Pleura, Mediastinum, and Lung. In Gerad M. Doherty, eds. Current Diagnosis and Treatment Surgery; Michigan, USA McGraw Hill Publishers; 2010, 18:317-19.

2. Light RW, Pleural effusions related to metastatic malignancies. In: Light RW, eds. Text book of Pleural Diseases. Philadelphia, USA: Lippincott Williams \& Wilkins publishers. 2013; 10; 153-188.

3. Peter W. Zimmer, MD; Mark Hill, MD; Kenneth Casey, MD, FCCP; Eric Harvey, PharmD; and Donald E. Low, MD. Prospective randomized trial of talc slurry VS bleomycin in pleurodesis for symptomatic malignant pleural effusions. Chest 1997; 112: 430-34.

4. Sai Yendamuri, Chukwumere Nwogu, and Todd L Demmy. Malignant pleural and pericardial effusions. In: Sabiston \& Spencer, eds. Surgery of the chest vol- 1; Philadelphia, USA: Saunders Publishers; 2010, 30:431-48.

5. Michacl Rolf Muller and Markus Marcher, Malignant pleural effusions. In: Jaroslaw Kuzdzat, eds. ESTS Text book thoracic surgery vol 1; Cracow, Poland: Medycyna Praktyczna Publishers; 2014, 13:201-12.

6. Ong K C, Indumathi V, Raghuram J and Ong Y Y. A comparative study of pleurodesis using talc slurry and bleomycin in the management of pleural effusions. Respirology 2000; 5: 99-103.
7. Fumihiko Muta, Shinzo Takamori, Toshihiro Matsuo, Yasonori Iwasaki, Koichi Yoshiyama et al. Changes in the pleural cavity by pleurodesis using talc or OK432 an experimental study. Surg today 2011; 41:111114.

8. Kwen-Tay Luh, MD, Pan-Chyr Yang, MD, PhD, SowHsong kuo, MD, Dun-Bing Chang, MD et al. Comparison of OK-432 and Mitomycin C pleurodesis for malignant pleural effusion caused by lung cancer. Cancer1992; 69: 674-679.

9. Springer et al. pleurodesis in patients with malignant pleural effusions: Talc slurry or bleomycin? Results of a prospective randomized trial. World journal of surgery 2004; 28:749-752.

10. Daniel TM, Tribble CG, Rodgers BM. Thoracoscopy and talc poundage for pneumothoraces and effusions. Ann Thorac surg.1990; 50:186-89.

11. Putnam J B, Light R W, Rodriguez R M at el. A randomized comparison of indwelling pleural catheter and doxycycline pleurodesis in the management of malignant pleural effusions. Cancer, 1999; 86:19921999.

12. Janssen J P, Collier G, Astoul P, Tassi G F et al. Saft of pleurodesis with talc poundage in malignant pleural effusions: a prospective cohort study. Lancet 2007; 369: 1535-9.

13. Kennedy L, Harley R A, Sahn S A, Strange C. Talc slurry pleurodesis, pleural fluid and histologic analysis. Chest 1995; 107: 1707-12.

14. Slegel R D, Schiffman F J. Systemic toxicity following intracavitary administration of bleomycin. Chest 1990; 98: 507.

15. Rinaldo J E, Owens G R, Roger R M. Adult respiratory distress syndrome following intra-pleural instillation of talc. J Thorac cardiovasc surg 1983; 85: 523-26.

16. Bouchama A, Chastre J, Gaudichat A et al. Acute pneumonitis with bilateral pleural effusions after talc pleurodesis. Chest 1984; 86: 795-95.

17. Kennedy L, Rush V W, Strange C et al. Pleurodesis using talc slurry. Chest 1994; 106:342-46. 